\section{Dr. Hmamouchi, et al reply}

We thank Dr. Toussirot and Dr. Dumoulin for their comments ${ }^{1}$ on our paper $^{2}$.

We are pleased to see that they recently published similar results in a group of 12 patients with spondyloarthritis (SpA). We thank the authors for pointing out that the software for visceral fat analysis is not validated on Hologic QDR 2000 devices. Indeed, our study was actually performed on a Hologic Delphi-W device, not a QDR 2000. We gave the results in $\mathrm{cm}^{2}$, because that is how the results were presented in the validation paper $^{3}$, knowing that the correlation between visceral fat area $\left(\mathrm{cm}^{2}\right)$, volume $\left(\mathrm{cm}^{3}\right)$, and mass $(\mathrm{g})$ on this software is completely linear $(\mathrm{r}=1, \mathrm{p}<0.0001)$; mass $(\mathrm{g})=$ area $\left(\mathrm{cm}^{2}\right) \times 4.8213072$, and volume $\left(\mathrm{cm}^{3}\right)=$ area $\left(\mathrm{cm}^{2}\right) \times 5.212224$ We agree that the relevance of the results is based on the validity of the measurement tool. The authors used the CoreScan software, which was validated by comparison to computed tomography (CT) scans ${ }^{4}$. We used Visceral Adipose Tissue software, which was also validated by comparison to $\mathrm{CT}$ scans $^{3}$.

Beyond these technical considerations, the issue is that the 2 studies indicate that a change in fat mass, and in visceral fat, is observed in patients with SpA receiving longterm administration of tumor necrosis factor- $\alpha$ blockers. Thus, we agree that these data are the basis for further studies on potential change in cardiovascular risk in these patients.

IHSANE HMAMOUCHI, MD, PhD, Paris Descartes University, Department of Rheumatology, Cochin Hospital, and Epidemiology and Biostatistics Unit, Sorbonne Paris Cité Research Center, Paris, France, and Mohammed V-Souissi University, Faculty of Medicine, Laboratory of
Biostatistics, Clinical Research and Epidemiology, El Ayachi Hospital, Rheumatology Department, Rabat, Morocco; CHRISTIAN ROUX, MD, PhD; SIMON PATERNOTTE, MD; SAMI KOLTA, MD; MAXIME DOUGADOS, MD, PhD; KARINE BRIOT, MD, PhD, Paris Descartes University, Department of Rheumatology, Cochin Hospital, and Epidemiology and Biostatistics Unit, Sorbonne Paris Cité Research Center, Paris, France. Address correspondence to Dr. I. Hmamouchi, Paris Descartes University, Department of Rheumatology, Cochin Hospital, and Epidemiology and Biostatistics Unit, Sorbonne Paris Cité Research Center, Paris, France. E-mail: ihsane.hmamouchi@gmail.com

\section{REFERENCES}

1. Toussirot E, Dumoulin G. Effects of TNF- $\alpha$ inhibitors on abdominal adiposity in patients with inflammatory rheumatic diseases. J Rheumatol 2014;41:2491-2.

2. Hmamouchi I, Roux C, Paternotte S, Kolta S, Dougados M, Briot $\mathrm{K}$. Early increase of abdominal adiposity in patients with spondyloarthritis receiving anti-tumor necrosis factor- $\alpha$ treatment. J Rheumatol 2014;41:1112-7.

3. Micklesfield LK, Goedecke JH, Punyanitya M, Wilson KE, Kelly TL. Dual-energy X-ray performs as well as clinical computed tomography for the measurement of visceral fat. Obesity 2012;20:1109-14.

4. Kaul S, Rothney MP, Peters DM, Wacker WK, Davis CE, Shapiro $\mathrm{MD}$, et al. Dual-energy X-ray absorptiometry for quantification of visceral fat. Obesity 2012;20:1313-8.

J Rheumatol 2014;41:12; doi:10.3899/jrheum.141160 